\title{
An empirical study on relationship between organizational culture and knowledge management: A case study of electric distribution in province of East Azarbayjan of Iran
}

\author{
Yahya Dadashkarimi
}

Department of Management, Bonab Branch, Islamic Azad University, Tehran, Iran

\begin{tabular}{|c|c|}
\hline ARTICLEINFO & AB S T RACT \\
\hline $\begin{array}{l}\text { Article history: } \\
\text { Received September 15, } 2011 \\
\text { Received in Revised form } \\
\text { October, 30, 2011 } \\
\text { Accepted 20 January } 2012 \\
\text { Available online } \\
\text { 26 January 2012 } \\
\text { Keywords: } \\
\text { Organizational culture } \\
\text { Knowledge Management } \\
\text { Creativity } \\
\text { Team work }\end{array}$ & $\begin{array}{l}\text { The purpose of this paper is to investigate the impact of organizational culture on knowledge } \\
\text { management. To learn more about the organizational culture, we choose five variables } \\
\text { including team-work, learning, discussion, management support and communication. The } \\
\text { propose study consists one main hypothesis and five sub hypotheses and it is performed among } \\
\text { all employees and management team of East Azarbayjan power supplier. The population of our } \\
\text { survey includes } 1482 \text { people and a sample of } 488 \text { people is chosen in this survey. A } \\
\text { questionnaire is distributed among all members and Cronbach Alpha is } 0.83 \text {, which yields } \\
\text { highly reliable results. The data are analyzed using SPSS software package with different non- } \\
\text { parametric methods and the results confirm all hypotheses in our survey. According to the } \\
\text { results of our survey, culture and communication play important role for the success of an idea } \\
\text { and knowledge creation. Negotiation, top management support and learning style are second } \\
\text { most important factors influencing knowledge management. }\end{array}$ \\
\hline
\end{tabular}

(C) 2012 Growing Science Ltd. All rights reserved.

\section{Introduction}

The new millennium has been nominated the century of creativity and innovation and companies with better ideas have chances of competition (Tsai et al., 2006; Richter \& Niewiem, 2009). During the past few years, there have been tremendous efforts on promoting employees to use their creativity for presenting new ideas to help organizations better compete with other competitors.

Ezati Jivan (2012) investigated the influence pattern of key factors affecting the purpose of organizational excellence consulting on the efficiency of businesses consulting services. He implemented his method on a real-world case study of small and medium-size food enterprises in Tehran province. His findings indicate that managers of small and medium-sized food enterprises in Tehran believe that providing accurate details of the quality of consulting programs, presenting a clear picture of the horizons faced by the organization and holding thank you ceremonies are among the mechanisms affecting the efficiency of management consulting services.

* Corresponding author. Tel: +98914-121-8151

E-mail addresses: dadashkarimi_2006@yahoo.com (Y. Dadashkarimi)

C 2012 Growing Science Ltd. All rights reserved. 
During the past decade, there were tremendous efforts on promoting creativity in different organizations. Christian (2002), for instance, presented a comprehensive study on the emergence of second generation knowledge management in engineering consulting. Bechina and Bommen (2006) presented a study on knowledge sharing practice by analyzing global Scandinavian consulting companies.

Information development and high development of technology in this century has created extended change in human life and information relies on observable intellectual capital. Economic developments of current century emphasize on this reality that creating value is owed to nonobservable investment more than, observable one. According to Bontis et al. (1996-2006), we see a decline on traditional resource such as tangible assets and an increase on knowledge. In this condition, new content such as mental investment has been attracted more attention. Therefore, intellectual capital is original resource for economic and other factors of traditional production are placed in next preference stages.

Intellectual capital shows knowledge entity of organizations performance. Bontis (1998) and Brooking (1998) believe that IC in one organization includes skills, ability to solve problem and methods of management. In fact, human capital is conceptual source of knowledge, which is obtained from clear and direct knowledge. Ferreira and Martines (2011) reported that human capital can change by social interaction, values correction and organizational obligation. Tamay et al. (2001) reported that high level of human capital can decrease the amount of time and necessary capital for obtaining information and solving problem. According to Freeeira and Martines (2011) human capital is a reason for organizations to rely on knowledge and skills of their employees to grow and efficiency develop. (Sharabati et al., 2010; Reed et al., 2006).

Knowledge management (KM) has become essential in today's economy, as knowledge today is regarded as main factor for production in all types of organizations. KM literature contains a range of thoughts that can be broadly classified into three main themes. The techno-centric theme looks at developing technology to improve knowledge creation and transfer (Johannessen et al., 2001). The organizational theme finds out ways to improve organization design to support knowledge processes (Davenport et al., 1998) while the ecological theme explores ways to better interact people, their identities and the environment (Kimble \& Bourdon, 2008). The resourcefulness of KM and its emphasis on developing knowledge for organizational improvements makes it inevitable for NGO sector (Vasconcelos et al., 2005).

In this paper, we present an empirical study to measure the relative importance of different factors on creating knowledge.

\section{The proposed study}

The proposed study of this paper considers five independent variables of freedom in action, cooperation, trust environment, different skills and self management as a key factor influencing team work efforts. There are four factors including individual, group, intra and extra organization activities on learning. The first factor is discussion, which is influenced by sharing, compromising, flexibility and tolerance. The fourth factor, top management support, is influenced by encouragement, support, risk acceptance and accepting mistakes. Finally, the last item is communication and there are four factors impact on, which are formal, informal communication and trust. All mentioned items could impact organizational culture and such culture could create an idea to a knowledge and a knowledge can be transmitted and stored and eventually helps creating new ideas. Fig 1. shows details of our proposed model. 


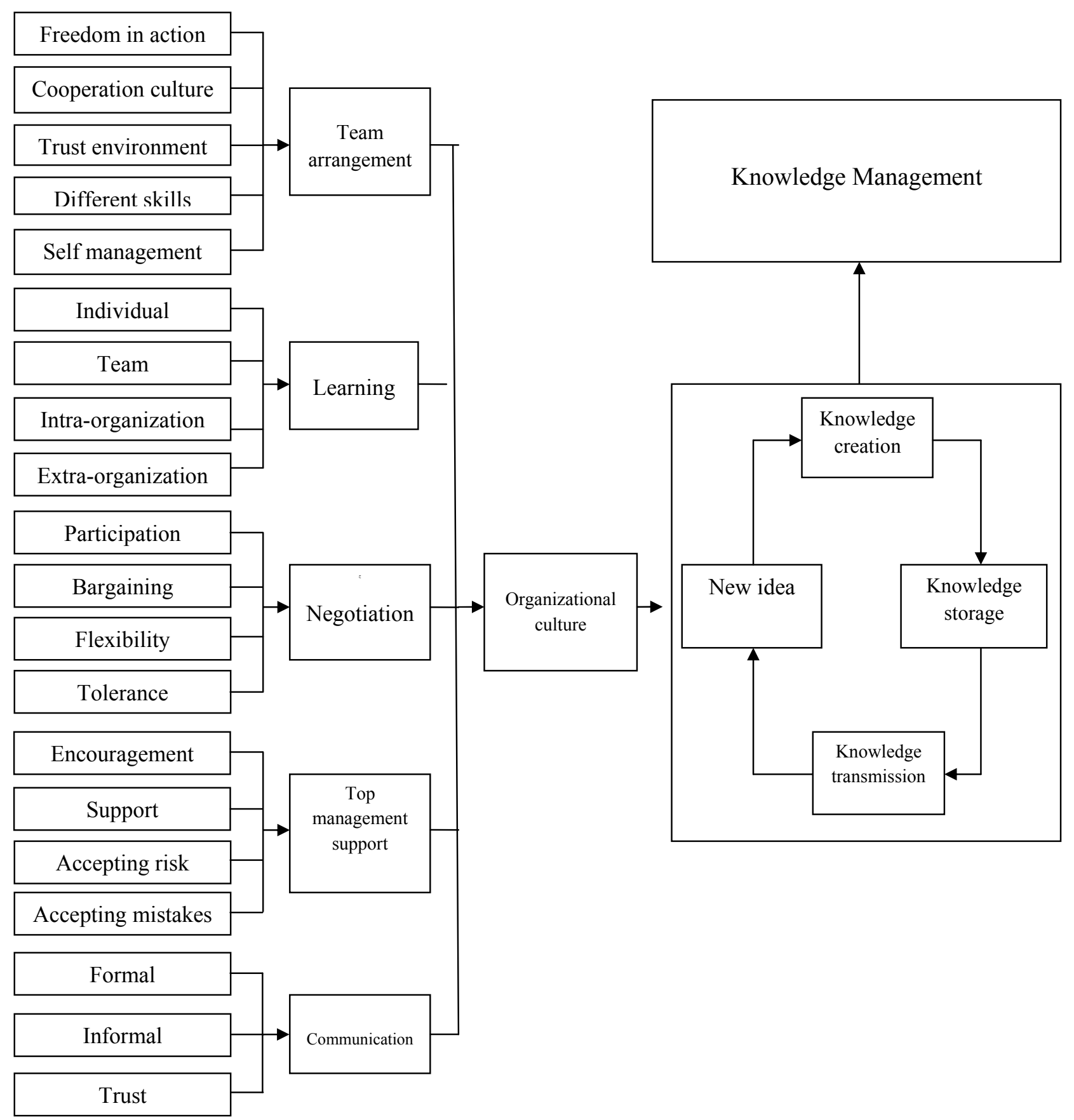

Fig. 1. The framework of the proposed model

\section{Results}

\subsection{Examination of different hypothesis}

\subsubsection{The first hypothesis: Team building and knowledge management}

The first hypothesis of this paper is associated with the relationship between building team and knowledge management, which is stated as follows,

H1: There is meaningful relationship between building team and knowledge management. 
We use Freedmand test as a non-parametric test to correlation among three or groups and it is more used for ordinal data. Table 1 shows details of ranking.

\section{Table 1}

The results of Freedman ranking $\left(\chi^{2}=186.629, \mathrm{df}=4\right.$, Asymp. Sig $\left.=0.000\right)$

\begin{tabular}{lccccc}
\hline Variable & Independence & Cooperation & Trust & Different skills & Self management \\
\hline Mean rank & 2.97 & 2.91 & 2.28 & 3.39 & 3.46 \\
\hline
\end{tabular}

As we can observe from the results of Table 1, the null hypothesis can be rejected with $\alpha=0.05$, which means there is a meaningful relationship between knowledge management and team factors. Table 2 shows the results of principal component analysis.

\section{Table 2}

The results of principle component analysis associated with team components

\begin{tabular}{lllllll}
\hline & \multicolumn{3}{c}{ Initial Eigenvalues } & \multicolumn{2}{c}{ Extraction sums of squared loadings } \\
Component & Total & \% of Variance & \% Cumulative & Total & \% of Variance & \% Cumulative \\
\hline Independence & 3.123 & 62.456 & 62.456 & 3.123 & 62.456 & 62.456 \\
Cooperation & 1.753 & 15.055 & 77.511 & & & \\
Trust & 1.560 & 11.206 & 88.717 & & \\
Different skills & 1.337 & 6.735 & 95.452 & & \\
Self management & 1.227 & 4.548 & 100.000 & & \\
\hline
\end{tabular}

As we can observe from the results of Table 2, having freedom and independence feeling is ranked one, 3.123, in terms of relative importance followed by cooperation (1.753), trust (1.560), having different skills (1.337) and self management (1.227). In other words, when a team is integrated, we need to give more freedom in action to have more creativity and innovation in team.

\subsubsection{The second hypothesis: Learning style and knowledge management}

The second hypothesis of this paper is associated with the relationship between factors influencing learning in team and knowledge management, which is stated as follows,

$\mathrm{H} 2$ : There is meaningful relationship between learning factors and knowledge management.

Table 3 shows details of ranking using freedman test.

\section{Table 3}

The results of Freedman ranking $\left(\chi^{2}=42.060, \mathrm{df}=3\right.$, Asymp. Sig $\left.=0.000\right)$

\begin{tabular}{lcccc}
\hline Variable & Personal & Group & Inter-organization & Extra-organization \\
\hline Mean rank & 2.36 & 2.34 & 2.51 & 2.78 \\
\hline
\end{tabular}

As we see from the results of Table 3 , the null hypothesis can be rejected with $\alpha=0.05$, which means there is a meaningful relationship between knowledge management and influencing factors in learning in team. Table 4 shows the results of principal component analysis for learning factors.

\section{Table 4}

The results of principle component analysis associated with the learning

\begin{tabular}{lllllcc}
\hline & \multicolumn{3}{c}{ Initial Eigenvalues } & \multicolumn{3}{c}{ Extraction sums of squared loadings } \\
Component & Total & \% of Variance & \% Cumulative & Total & \% of Variance & \% Cumulative \\
\hline Personal & 1.361 & 42.015 & 42.015 & 2.361 & 59.015 & 59.015 \\
Group & 1.361 & 42.015 & 84.030 & & & \\
Intra-organization & 0.389 & 9.623 & 93.653 & & & \\
Extra-organization & 0.360 & 6.347 & 100.00 & & & \\
\hline
\end{tabular}


As we can observe from the results of Table 4, The first two items have more impact than other two ones.

\subsubsection{The third hypothesis: Negotiation and knowledge management}

The third hypothesis of this paper is associated with the relationship between factors influencing discussion and negotiation in team and knowledge management, which is as follows,

H3: There is meaningful relationship between discussion factors and knowledge management.

Table 5 shows details of ranking using freedman test.

Table 5

The results of Freedman ranking $\left(\chi^{2}=117.546, \mathrm{df}=3\right.$, Asymp. Sig $\left.=0.000\right)$

\begin{tabular}{lcccc}
\hline Variable & Personal & Group & Inter-organization & Extra-organization \\
\hline Mean rank & 2.66 & 2.51 & 2.82 & 2.02 \\
\hline
\end{tabular}

As we see from the results of Table 5, the null hypothesis can be rejected with $\alpha=0.05$, which means there is a meaningful relationship between knowledge management and discussion factors. Table 6 shows the results of principal component analysis for discussion components.

\section{Table 6}

The results of principle component analysis associated with the negotiation

\begin{tabular}{|c|c|c|c|c|c|c|}
\hline \multirow[b]{2}{*}{ Component } & \multicolumn{3}{|c|}{ Initial Eigenvalues } & \multicolumn{3}{|c|}{ Extraction sums of squared loadings } \\
\hline & Total & $\%$ of Variance & $\%$ Cumulative & Total & $\%$ of Variance & $\%$ Cumulative \\
\hline Participation & 2.488 & 62.211 & 62.211 & 2.488 & 62.211 & 62.211 \\
\hline Bargaining & 1.645 & 16.122 & 78.333 & & & \\
\hline Flexibility & 0.503 & 12.582 & 90.915 & & & \\
\hline Tolerance & 0.363 & 9.085 & 100.00 & & & \\
\hline
\end{tabular}

As we can observe from the results of Table 6, participation and bargaining play important role on negotiation while flexibility and tolerance are not as important as the other two factors.

\subsubsection{The fourth hypothesis: Top management support and knowledge management}

The third hypothesis of this paper is associated with the relationship between factors influencing top management support and knowledge management as follows,

H4: There is meaningful relationship between top management support and knowledge management.

Table 7 shows details of ranking using freedman test for the relationship between factors influencing top management support and knowledge management.

\section{Table 7}

The results of Freedman ranking $\left(\chi^{2}=135.259, \mathrm{df}=3\right.$, Asymp. Sig $\left.=0.000\right)$

\begin{tabular}{lcccc}
\hline Variable & Encouragement & Support & Accepting risk & Accepting mistake \\
\hline Mean rank & 2.60 & 2.46 & 2.92 & 2.02 \\
\hline
\end{tabular}

As we see from the results of Table 7, the null hypothesis can be rejected with $\alpha=0.05$, which means there is a meaningful relationship between knowledge management and top management support. Table 8 shows the results of principal component analysis for top management support. 
As we can observe from the results of Table 8, encouragement plays the most important role for knowledge management. However, the other three factors are not as important as the first item.

Table 8

The results of principle component analysis associated with top management support

\begin{tabular}{lcccccc}
\hline & \multicolumn{3}{c}{ Initial Eigenvalues } & \multicolumn{3}{c}{ Extraction sums of squared loadings } \\
Component & Total & \% of Variance & \% Cumulative & Total & \% of Variance & \% Cumulative \\
\hline Encouragement & 2.461 & 61.527 & 61.527 & 2.461 & 61.527 & 61.527 \\
Support & 0.900 & 22.491 & 84.018 & & & \\
Accepting risk & 0.383 & 9.563 & 93.581 & & & \\
Accepting mistake & 0.257 & 6.419 & 100.00 & & & \\
\hline
\end{tabular}

\subsubsection{The fifth hypothesis: Communication and knowledge management}

The last hypothesis of this paper is associated with the relationship between factors influencing communication and knowledge management, which is as follows,

H5: There is meaningful relationship between communication and knowledge management.

Table 9 shows details of ranking using freedman test for the relationship between factors influencing communication and knowledge management.

\section{Table 9}

The results of Freedman ranking $\left(\chi^{2}=132.296, \mathrm{df}=3\right.$, Asymp. Sig $\left.=0.000\right)$

\begin{tabular}{lccc}
\hline Variable & Formal & Informal & Trust \\
\hline Mean rank & 1.65 & 2.37 & 1.98 \\
\hline
\end{tabular}

As we see from the results of Table 9, the null hypothesis can be rejected with $\alpha=0.05$, which means there is a meaningful relationship between knowledge management and communication. Table 10 shows the results of principal component analysis for this item.

\section{Table 10}

The results of principle component analysis associated with communication

\begin{tabular}{|c|c|c|c|c|c|c|}
\hline \multirow[b]{2}{*}{ Component } & \multicolumn{3}{|c|}{ Initial Eigenvalues } & \multicolumn{3}{|c|}{ Extraction sums of squared loadings } \\
\hline & Total & $\%$ of Variance & $\%$ Cumulative & Total & $\%$ of Variance & $\%$ Cumulative \\
\hline Formal & 1.176 & 26.123 & 26.123 & 2.176 & 72.544 & 72.544 \\
\hline Informal & 2.174 & 72.123 & 98.246 & & & \\
\hline Trust & 0.340 & 1.754 & 100.00 & & & \\
\hline
\end{tabular}

As we can observe from the results of Table 10, informal communication plays the most important role for knowledge management and the other two items come in other priorities.

\subsection{The summary of results}

As we observed earlier, all five hypothesis associated with the proposed study of this paper have been confirmed, which means different factors shown in Fig. 1 impact the creation of knowledge management, significantly. However, one primary question is on measuring the relative importance of each of these components. Table 11 demonstrates details of our ranking using Pearson correlation test.

\section{Table 11}

The results of Pearson correlation test 


\begin{tabular}{llllll}
\hline Variable & $\begin{array}{l}\text { The culture of } \\
\text { team work }\end{array}$ & Communication & Negotiation & $\begin{array}{l}\text { Top management } \\
\text { support }\end{array}$ & $\begin{array}{l}\text { Learning } \\
\text { style }\end{array}$ \\
\hline Correlation & 3.002 & 3 & 2.502 & 2.5 & 2.495 \\
\hline
\end{tabular}

As we can observe from the results of Table 11, culture and communication play important role for the success of an idea and knowledge creation. Negotiation, top management support and learning style are second most important factors influencing knowledge management.

\section{Conclusion}

The new millennium has been nominated the century of creativity and innovation and companies with better ideas have chances of competition. In this paper, we have presented an empirical study to measure the effects of different factors on knowledge creation as well as knowledge management. We have distributed a questionnaire among various people who worked for a power transmission company located in East Azarbayjan, Iran. The results indicated that the culture of team-work as well as communication are the most important factors influencing knowledge management. The other important factors including negotiation top management support and learning style. These items are believed have important role on improving pure ideas in this organization.

\section{Acknowledgment}

The authors would like to thank the anonymous referees for their constructive comments on this paper.

\section{References}

Bechina A. A., \& Bommen T. (2006). Knowledge sharing practice: Analysis of global Scandinavian consulting company. Electronic Journal of Knowledge Management, 4(2), 109- 116.

Bontis, N. (1997). Intellectual Capital Questionnaire. Institute for Intellectual Capital Research; Canada: Hamilton.

Bontis, N., Crossan, M., \& Hulland, J. (2002). Managing an organizational leaning system by aligning stocks and flows. Journal of Management Studies, 39(4), 437-466.

Bontis, N. (1996). There's a price on your head: Managing intellectual capital strategically. Ivey Business Quarterly, 60(4), 40-47.

Bontis, N. (1998). Intellectual Capital: An Exploratory study that develops measures and models. Management Decision, 36(2), 63-76.

Bontis, N., Dragonetti, N.C., Jacobsen, K. \& Roos, G. (1999). The Knowledge toolbox: a review of the tools available to measure and manage intangible resources. European Management Journal, 17(4), 391-401.

Brooking, A. (1996). Intellectual Capital. International Thompson Business Press, London.

Christian K. (2002). The emergence of second generation knowledge management in engineering consulting. International Council for R \& D in Building, and construction Conference.

Davenport, T. H., De Long, D. W., \& Beers, M. C. (1998). Successful KM projects. Sloan Management Review, 39(2), 43-57.

Ezati Jivan, M. (2012). The influence pattern of key factors affecting the purpose of organizational excellence consulting on the efficiency of businesses consulting services (A case study of small and medium-size food enterprises in Tehran province). Management Science Letters,2(2), 713726.

Ferreira, A.I, \& Martinez, L.F. (2011). Intellectual capital: perceptions of productivity and Investment. RAC, Curitiba, 15(2), 249-260. 
Johannessen, J. A., Olaisen, J., \& Olsen, B. (2001). Mismanagement of tacit knowledge: The importance of tacit knowledge, the danger of information technology and what to do about it. International Journal of Information Management, 21(1), 3-20.

Kimble, C., \& Bourdon, I. (2008). Some success factors for the communal management of knowledge. International Journal of Information Management, 28(6), 461-467.

Reed, K. K., Lubatkin, M., \& Srinivasan, N. (2006). Proposing and testing an intellectual capitalbasedview of the firm. Journal of Management Studies, 43(4), 867-893.

Richter, A., \& Niewiem, S. (2009). Knowledge transfer across permeable boundaries: An empirical study of clients' decisions to involve management consultants. Scandinavian Journal of Management, 25(3), 275-288.

Sharabati, A., Jawad, S., \& Bontis, N. (2010). Intellectual capital and business performance in the pharmaceutical sector of Jordan. Management Decision, 48(1), 105-131.

Tsai, C.H., Chang, C.L., \& Chen, L. (2006). A Case Study of Knowledge management (formation consulting company International). Journal of the Computer, the Internet and Management, 14(3), 60-78.

Vasconcelos, J., Seixas, P., Chris, K., \& Lemos, P. (2005). KM in Non-Governmental Organizations: A Partnership for the Future, Proceedings of the 7th International Conference on Enterprise Information Systems (ICEIS 2005), Miami, USA, May 24-28, ISBN: 972-8865-19-8. 